\title{
Serum Concentrations of DDT and DDE among Malaria Control Workers in the Amazon Region
}

\author{
Celso P. Ferreira, Ana Cecilia A.X. De-Oliveira and Francisco J.R. Paumgartten \\ Laboratory of Environmental Toxicology, Department of Biological Sciences, National School of Public Health, \\ Oswaldo Cruz Foundation, Brazil
}

\begin{abstract}
Serum Concentrations of DDT and DDE among Malaria Control Workers in the Amazon Region: Celso P. Ferreira, et al. Laboratory of Environmental Toxicology, Department of Biological Sciences, National School of Public Health, Oswaldo Cruz Foundation, Brazil-Background: In Brazil, DDT was used to control malaria-transmitting mosquitoes from 1945 to 1997. Owing to concerns about the potential adverse health consequences of long-term exposures to DDT, workers of the National Foundation of Health (FNS) who had taken part in malaria control operations in the Amazon region were monitored for blood levels of DDT as well as for their health status between 1997 and 2001. Objectives: To evaluate blood levels of DDT/DDE and elimination half-life $\left(t_{1 / 2}\right)$ of $p p^{\prime}-\mathrm{DDE}$ in malaria control personnel. Methods: Levels of DDT and $p p^{\prime}$-DDE were measured in the blood serum of 119 public health workers (32-67 yr old, 117 males) from Pará state-Brazil. Serum levels of DDT/ DDE were determined by gas chromatography with electron capture detection. Results: Blood serum levels of $\Sigma$-DDT and pp'-DDE (mean \pm SD) were as follows $(\mu \mathrm{g} / \mathrm{l})$ : February $1997(\mathrm{~N}=110), 231.5 \pm 366.4$ (156.9 \pm 236.8 as pp'-DDE); February $1998(\mathrm{~N}=116)$, $126.4 \pm 86.6\left(83.0 \pm 54.6\right.$ as $\left.p p^{\prime}-\mathrm{DDE}\right)$; May 2001 $(\mathrm{N}=117), 50.4 \pm 53.3\left(39.4 \pm 37.6\right.$ as $\left.p p^{\prime}-\mathrm{DDE}\right)$. The half-life (mean \pm SD) of $p p^{\prime}-\mathrm{DDE}$ was $29.5 \pm 22.7 \mathrm{mo}$. Conclusions: Concentrations of $\Sigma$-DDT/ pp'-DDE in the blood serum of malaria control workers were much higher than levels found in the general population in Brazil and elsewhere. The half-life of pp'-DDE (29.5 mo) estimated for this group of occupationally exposed male adults was shorter than $t_{1 / 2}$ values previously reported for environmentally exposed subjects.

(J Occup Health 2011; 53: 115-122)
\end{abstract}

Received Aug 25, 2010; Accepted Nov 25, 2010

Published online in J-STAGE Jan 11, 2011

Correspondence to: FJR Paumgartten, Laboratory of Environmental Toxicology, Department of Biological Sciences, National School of Public Health, Oswaldo Cruz Foundation, Av.Brasil 4365, Rio de Janeiro, RJ 21045-900, Brazil (e-mail: paum@ensp.fiocruz.br)
Key words: DDE blood levels, DDE half-life, DDT spraying, Malaria control, Occupational exposure, Pesticides

Dichlorodiphenyltrichloroethane (DDT) was first used for malaria control in Brazil in 1945, when a team of SESP (Serviço Especial de Saúde Pública / Public Health Special Service) agents, under the leadership of J.D. Williams, sprayed it on the walls of all houses of the Amazon town of Breves, located in Marajó island, a highly endemic area at that time ${ }^{1)}$. Malaria was drastically reduced in Breves and in the following years, DDT-spraying was extended to other malarious areas, and by 1954 it had been applied to over 3 million houses ${ }^{1}$. The fight against malaria was very successful until 1970 when the disease reached its lowest incidence rate $(50,500$ cases/yr) in the country. Since then, however, malaria has re-emerged and the number of cases rose to 443,000 in 1986, 630, 747 in 1999 and 545, 696 in 2006, more than $99 \%$ of which were in the Amazon region ${ }^{2}$. DDT was employed against malaria until 1997, when an internal directive of FNS (Fundação Nacional de Saúde/National Foundation of Health) forbade its use in any vector control program ${ }^{3}$. Although DDT and other persistent organic pollutants (POPs) - with a few exceptions - had been banned for use in agriculture in 1985, their use in public health campaigns remained authorized $^{4)}$ until 1997. In 1998, the Ministry of Health cancelled the previously published monographs of DDT and other POPs prohibiting their use for any purpose in Brazil ${ }^{5)}$. Later, in 2009, the Brazilian parliament passed the DDT Law that states that manufacturing, importation and exportation, storing, marketing and use of DDT are strictly forbidden in the country ${ }^{6}$. The DDT Law also states that in 2011 the Federal government has to assess the environmental and health impact of the past use of DDT for disease vector control in the Amazon region ${ }^{6}$.

As a consequence of malaria control operations in Brazil, thousands of workers were exposed to DDT from 1945 through 1997. From 1997 onwards, hundreds of FNS malaria control personnel had their blood levels of 
DDT and general health status checked and in May 2001, 119 from Pará state were also evaluated by a comprehensive battery of medical, neurological, haematological and clinical chemistry examinations. This paper reports the exposure data of this group of 119 workers who took part in malaria control activities in the Amazon region. Additionally, since most of these DDT-sprayers had three sequential blood level determinations between 1997 and 2001, elimination half-lives of $p p$ '-dichlorodiphenyldichloroethylene ( $p p^{\prime}$-DDE) were estimated as well.

\section{Materials and Methods}

Medical and occupational records of 119 FNS workers (32-67 yr old, 117 males) who had been involved in malaria control activities ("Marabá" and "Conceição-doAraguaia" municipalities, Pará state, Brazil) were analyzed. In 2001, all workers were evaluated with a set of clinical, neurological (EEG, EMG) and laboratory exams. The study was approved by the Research Ethics Board of the National School of Public Health (Oswaldo Cruz Foundation - FIOCRUZ) and also by the National Foundation of Health (FNS).

Blood samples $(10 \mathrm{~m} l)$ were drawn from an arm vein and collected in silicone-coated Vacutainer ${ }^{\circledR}$ tubes without anticoagulants. Immediately after clotting, serum was separated by centrifugation and serum samples were sent to the Adolfo Lutz Institute, São Paulo, where they were further analyzed as described elsewhere ${ }^{7)}$. Briefly, organochlorine residues were extracted with $n$-hexane (residue grade) and analyzed by gas chromatography with electron capture detection $\left({ }^{63} \mathrm{Ni}\right)$. Nitrogen (high purity grade) was the carrier gas at $30 \mathrm{ml} / \mathrm{min}$ and chromatographic parameters were as follows: column temperature, 60 to $190^{\circ} \mathrm{C}, 25^{\circ} \mathrm{C} / \mathrm{min}, 190$ to $280^{\circ} \mathrm{C}, 5^{\circ} \mathrm{C} / \mathrm{min}, 280^{\circ} \mathrm{C}(2 \mathrm{~min})$; injector temperature, $250^{\circ} \mathrm{C}$; and detector temperature, $320^{\circ} \mathrm{C}$. A capillary column $(30 \mathrm{~m} \times 0.32 \mathrm{~mm} \times 0.25 \mu \mathrm{m})$ with $5 \%$ phenyl methyl siloxane was used. The limits for quantification were 2.8 and $1.4 \mu \mathrm{g} / l$ for $p p$ '-DDT and $p p^{\prime}$ DDE, respectively. Most workers had their serum levels of $p p^{6}$-DDT/ $p p^{6}$-DDE determined in 1997, 1998 and 2001. Elimination half-lives $\left(\mathrm{t}_{1 / 2}\right)$ were calculated by dividing $0.693(\ln 2)$ by the slope of the least square regression of natural logarithms of $p p$ '-DDE concentrations versus time ${ }^{8)}$.

The cumulative occupational dose of DDT was estimated by multiplying the number of working days by the average amount of DDT sprayed per day. The recommended dosage of technical DDT for residual spraying on walls was $2 \mathrm{~g} / \mathrm{m}^{2}$. In practical terms, the average amount of DDT used per house in the Amazon region was $500 \mathrm{~g}$, i.e, the DDT load, while one worker sprayed on average 5 houses per day. Therefore, it was estimated that occupational dose per sprayer per working day was 2,500 $\mathrm{g}$ of technical DDT. The estimate of DDT daily exposure was multiplied by the number of working
Table 1. Characteristics of the group of public health workers evaluated in this study

\begin{tabular}{lc}
\hline $\mathrm{N}$ (males / females) & $119(117 / 2)$ \\
Age $(\mathrm{yr})($ Mean $\pm \mathrm{SD})$ & $43.1 \pm 7.8$ \\
Body Mass Index $\left(\mathrm{BMI} ; \mathrm{kg} / \mathrm{m}^{2}\right)($ Mean $\pm \mathrm{SD})$ & $26.5 \pm 3.6$ \\
$\begin{array}{l}\text { Education level (highest degree achieved): } \\
\quad \text { Primary }\end{array}$ & $92(77.3 \%)$ \\
$\quad$ Secondary & $27(22.7 \%)$ \\
Occupation & $106(89.1 \%)$ \\
$\quad$ Insecticide sprayer & $9(7.6 \%)$ \\
$\quad$ Driver & $2(1.6 \%)$ \\
$\quad$ Laboratory technician & $1(0.8 \%)$ \\
$\quad$ Service man & $1(0.8 \%)$ \\
$\quad$ Administrative worker & $84.3 \pm 51.3$ \\
Occupational exposure to DDT (Mean \pm SD) & \\
$\quad$ Duration (mo) & $4,308.9 \pm 2,453.2$ \\
Cumulative occupational dose $(\mathrm{kg})$ & $94.1 \pm 59.0$ \\
$\quad$ Time elapsed since last DDT spraying (mo) & \\
\hline
\end{tabular}

All workers took part in malaria control operations in the Amazon region before 1997. Data presented below are from May 2001 when malaria control workers underwent a comprehensive medical examination and had their blood levels of DDT / DDE determined.

days in each month and finally summed up to provide the cumulative occupational dose of DDT.

Statistical analyses were conducted using SPSS (version 11) and Graph Pad Prism 4 software. Descriptive statistics, linear regression, analysis of variance (ANOVA) for repeated measures, chi-square test, and Spearman's rank correlation coefficient were used. In all cases, a difference was considered as statistically significant when $p<0.05$.

\section{Results}

General features of the group of public health workers evaluated in this study

All public health workers (117 males and 2 females) examined in this study reported having had a long contact with DDT during malaria control operations in the Amazon region. In May 2001, they were between 32 and 67 yr old (mean $\pm \mathrm{SD}, 43.1 \pm 7.8)$, and had a body mass index (BMI) ranging from 19.7 to $41.1 \mathrm{~kg} / \mathrm{m}^{2}$ (mean $\pm \mathrm{SD}, 26.5 \pm 3.6$ $\mathrm{kg} / \mathrm{m}^{2}$ ) (Table 1). The highest education level achieved by these workers were primary $(77.3 \%)$ or secondary education degree $(22.7 \%)$ (Table 1). Most public health workers evaluated in this study were either insecticide sprayers $(89.1 \%)$ or drivers $(7.6 \%)$ who handled and transported DDT to endemic areas (Table 1). The occupation of the remaining FNS employees (3.3\%, i.e., two laboratory technicians, one service man and one administrative worker) did not involve direct contact with insecticides at the workplace. The estimated duration of 

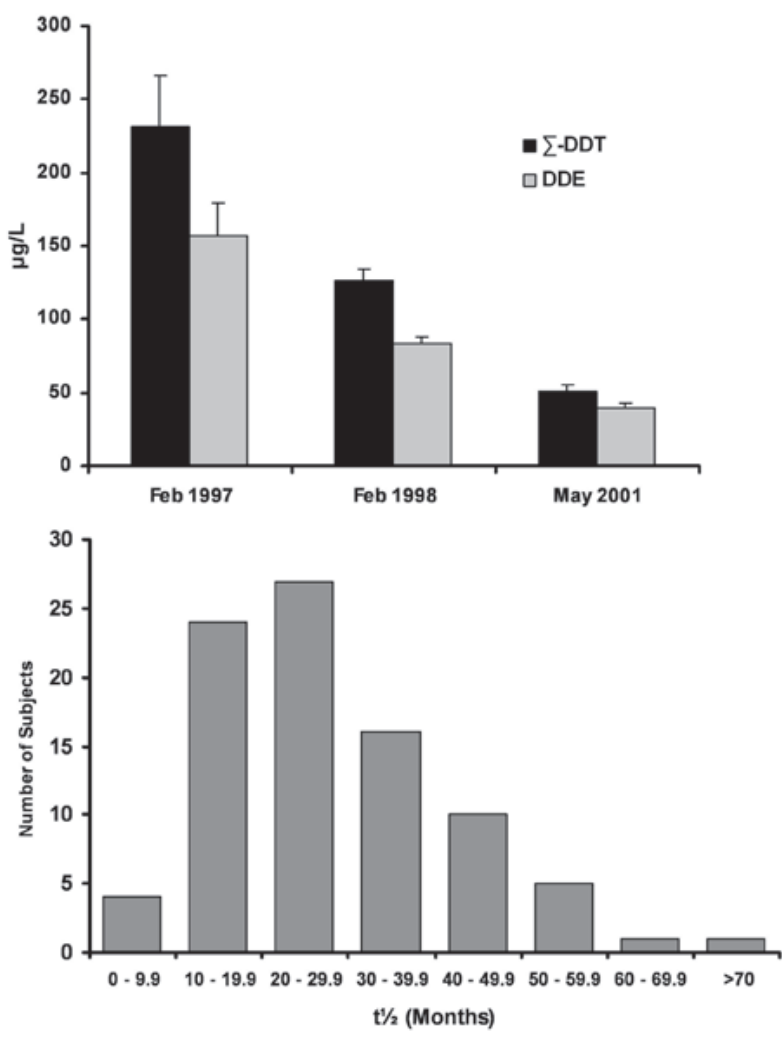

Fig. 1. Panel A (top): Levels $(\mu \mathrm{g} / l)$ of $\Sigma$-DDT (sum of all DDT derivative residues) and $p p^{\prime}-\mathrm{DDE}$ in the blood serum of malaria control workers $(\mathrm{N}=110$; mean $\pm \mathrm{SEM})$ in 1997 , 1998 and 2001. DDT was used for malaria control in the Brazilian Amazon region from 1945 up to 1997. Panel B (bottom): Distribution of $p p$ '-DDE half-life values $\left(\mathrm{t}_{1 / 2}\right)$ in this group of malaria control workers $(\mathrm{N}=91)$. Half-lives (mo) were estimated from three serial measurements of $p p^{\prime}$-DDE levels in the blood serum between 1997 and 2001. Statistical comparisons (top panel) were made by ANOVA for repeated measures. Differences $(p<0.01)$ are indicated as follows: $(*) \neq$ from 1997 values; $(* *) \neq$ from 1998 values.

occupational exposure to DDT, i.e., the sum of working months handling and / or spraying this insecticide, ranged from 11 to 340 mo (mean \pm SD was $84.3 \pm 51.3 \mathrm{mo}$ ) while the estimated cumulative dose (the number of working days times the average amount of DDT sprayed per working day) was 4,308.9 $\pm 2,453.2 \mathrm{~kg}$ (mean $\pm \mathrm{SD}$ ) (Table 1). The mean time (mean $\pm \mathrm{SD}$ ) between the last DDT spray and the interview and medical examination (May 2001) was 94.1 \pm 59.0 mo (Table 1).

\section{Blood serum levels of DDT and pp'-DDE}

The malaria control workers had their blood serum levels of DDT and metabolites measured in 1997 (February), in 1998 (February) and in 2001 (May). As shown in Fig. 1A and Table 2, mean serum levels of
$\Sigma$-DDT and $p p$ '-DDE markedly decreased between 1997 and 2001. Although showing no discernible elevation between 1997 (mean \pm SD: $0.67 \pm 0.17$ ) and 1998 (0.68 \pm 0.13 ), the ratio $p p$ '-DDE/ $\Sigma$-DDT was significantly higher in $2001(0.84 \pm 0.18, p<0.05)$ (Table 2). The results indicate that public health workers' body burden of DDT and $p p$ '-DDE markedly decreased after 1997 when DDT spraying for malaria control was discontinued. No correlation was found between estimated cumulative occupational doses of DDT and serum levels of $p p^{\prime}$-DDE (Fig. 2).

\section{Elimination half-lives of $p p^{\prime}-D D E$}

Since DDT spraying ceased in 1997, and most public health workers had three sequential measurements of $p p$ 'DDE serum levels between 1997 and 2001, the $p p$ '-DDE elimination half-life $\left(\mathrm{t}_{1 / 2}\right)$ was estimated as suggested by Wolff et al. ${ }^{8}$. Twenty-two individuals showed no decline in $\Sigma$-DDT and $p p$ '-DDE serum levels between 1997 and 2001. The elimination half-life (mean $\pm \mathrm{SD}$ ) of $p p$ '-DDE for the remaining public health workers $(\mathrm{N}=91)$ was 29.5 \pm 22.7 mo. The median half-life of $p p '-D D E$ was $28 \mathrm{mo}$, if the whole group of 113 workers was taken into account, and $24 \mathrm{mo}$, if only those workers $(\mathrm{N}=91)$ who showed a downward trend of $p p$ '-DDE serum levels were included. To calculate the median $p p$ '-DDE half-life in the first case, half-lives of the 22 workers who showed no decline of $p p$ '-DDE blood levels were assumed to be infinite.

As shown in Fig. 1B, there was a marked interindividual variability of estimated $p p$ '-DDE half-life values. In this group of highly exposed public health workers $p p$ '-DDE half-life did not correlate either with BMI or with age (Spearman's rank correlation coefficients, $r_{\mathrm{s}}=0.09$ and $p=0.408$, and $r_{\mathrm{s}}=0.121$ and $p=0.463$, respectively).

\section{Discussion}

Occupational exposure to DDT during malaria control operations

Data presented in this paper indicate that public health workers who took part in malaria control operations in the Amazon region had high $\Sigma$-DDT and $p p$ '-DDE body burdens. As shown in Table 3, in 1997, levels of $\Sigma$-DDT and $p p$ '-DDE in the blood of malaria control workers were much higher than the levels found in the general population of Rio de Janeiro state where, except for a few cases of focal spraying for leishmaniasis control, DDT had not been used for decades ${ }^{7,9,10)}$. Blood levels of $\Sigma$-DDT and $p p$ '-DDE in this group of public health workers were also higher than those reported for the general population of São Paulo and Bahia states in the 1980s and early 1990s ${ }^{11-13)}$. Furthermore, levels of $\Sigma$-DDT and $p p$ '-DDE found in this study were comparable or somewhat higher than those reported for vector-control workers from other regions of the country in the 1980s and 1990s (Table 3). Since the use of DDT 
Table 2. Blood serum levels of $\Sigma$-DDT and $p p^{\prime}$-DDE $(\mu \mathrm{g} / l)$ and ratios of $p p^{\prime}$-DDE/ $\sum$-DDT in workers who had taken part in malaria control activities in the Amazon region (Southern Para sate), Brazil, until 1997 when DDT use was discontinued

\begin{tabular}{cccc}
\hline Year: & 1997 & 1998 & 2001 \\
\hline $\mathrm{N}$ & 110 & 116 & 117 \\
$\Sigma$-DDT $(\mu \mathrm{g} / l)$ & & & \\
Mean \pm SD & $231.5 \pm 366.4$ & $126.4 \pm 86.6$ & $50.43 \pm 53.3$ \\
Median (min-max) & $184.8(5.3-3839.8)$ & $110.3(4.1-479.1)$ & $32.8(3.3-357.9)$ \\
$p p^{\prime}$-DDE $(\mu \mathrm{g} / l)$ & & \\
Mean \pm SD & $156.9 \pm 236.8$ & $83.0 \pm 54.6$ & $39.4 \pm 37.6$ \\
Median (min-max) & $119.8(4.6-513.8)$ & $74.0(3.4-303.2)$ & $27.7(2.3-284.1)$ \\
$p p^{\prime}$-DDE $(\mu \mathrm{g} / \mathrm{g}$ of lipids) & & - & $685.0 \pm 192.3$ \\
Mean \pm SD & - & - & $657.5(164.5-1433.0)$ \\
Median (min-max) & - & & $0.84 \pm 0.18$ \\
$p p^{\prime}$-DDE / $\Sigma$-DDT & $0.67 \pm 0.17$ & $0.70(0.10-1.00)$ & $0.90(0.08-1.00)$ \\
Mean \pm SD & $0.70(0.03-1.00)$ & & \\
Median (min-max) &
\end{tabular}

for vector control ceased in 1997, the decline of $\Sigma$-DDT and $p p^{\prime}$-DDE blood levels and the elevation of $p p^{\prime}-$ DDE/ $\sum$-DDT ratios between 1997 and 2001 (Fig. 1A, Table 2) support the view that the occupational exposure made a substantial contribution to the body burdens of $\Sigma$-DDT and $p p$ '-DDE among these public health workers. Nonetheless, we found no correlation between cumulative occupational dose and blood levels of $p p$ '-DDE in 1997 (Fig. 2). The lack of correlation between cumulative doses and body burdens may have arisen from a variety of factors including the existence of marked differences among individuals regarding personal hygiene habits (such as washing hands before eating, drinking, or smoking, and showering and changing worn clothes after spraying) and the way the sprayers handled DDT at work, as well as the wide dispersion of $p p$ '-DDE half-life values (Fig. 1B) and the variable time interval between the last DDT spray and the blood sampling in 1997 (Table 1).

The exposure of malaria control sprayers to DDT occurred through inhalation (during insecticide spraying on walls of dwellings), dermal contact and ingestion of contaminated foods and water. Since at that time most public health workers regarded DDT as a harmless substance, it was carelessly handled and, as a rule, no personal protective equipment (PPE) was used during handling, transportation, mixing and application on the houses. The Amazon climate is warm and humid; thus, wearing long-sleeved shirts at work was an exception rather than the rule among sprayers. Under those conditions, dermal exposure to DDT probably occurred through a large unclothed skin area that included face, hands, forearms, neck, and "V" of chest. Compared with the oral route, however, respiratory and dermal routes seem to have been less important routes of entry for DDT

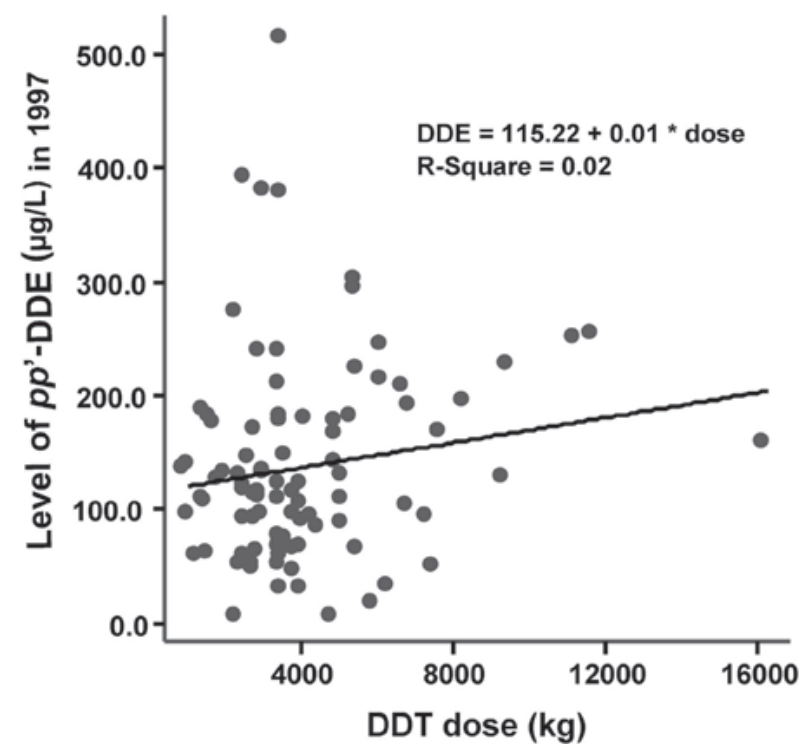

Fig. 2. Plot of blood serum levels $(\mu \mathrm{g} / l)$ of $p p$ '-DDE in 1997 against cumulative occupational doses of DDT $(\mathrm{kg})$ received by malaria control workers. DDT spraying for malaria control in the Brazilian Amazon region was discontinued in 1997. Correlation between serum levels of $p p^{\prime}-\mathrm{DDE}$ and cumulative doses of DDT was not significant (Spearman's rank correlation coefficient $\mathrm{r}_{\mathrm{s}}=$ $0.133, p=0.209)$.

into the body. Since most DDT particles are larger than $250 \mu \mathrm{m}$, they are deposited in the upper respiratory tract and are eventually swallowed after inhalation ${ }^{14)}$. The percutaneous absorption of DDT from dust and aqueous emulsion formulations is very poor as well ${ }^{15)}$. It was demonstrated, however, that some DDT persists, for days 
Table 3. Blood serum levels of $\Sigma$-DDT and $p p^{\prime}$-DDE $(\mu \mathrm{g} / l)$ found in occupationally exposed individuals and in the general population (adults) in Brazil

\begin{tabular}{|c|c|c|c|c|c|}
\hline \multirow[t]{2}{*}{ Exposure } & \multirow[t]{2}{*}{ State } & \multirow[t]{2}{*}{$\mathrm{N}$} & \multicolumn{2}{|c|}{ Concentration $(\mu \mathrm{g} / l)$} & \multirow[t]{2}{*}{ Study, year } \\
\hline & & & $p p^{\prime}-\mathrm{DDE}$ & $\Sigma$-DDT & \\
\hline \multicolumn{6}{|c|}{ General population } \\
\hline GP & RJ & 30 & $115.0^{+}$ & $336.0^{+}$ & Almeida, $1972^{21)}$ \\
\hline GP & ES & 11 & $117.0^{+}$ & $194.0^{+}$ & Almeida, $1972^{21)}$ \\
\hline GP & SP & 42 & $23.9^{+}$ & $26.8^{+}$ & Fernícola and Azevedo, $1982^{11)}$ \\
\hline GP & GO & 51 & $10.0-1,000.0^{+++}$ & - & Lara et al., 198722) \\
\hline GP & BA & 50 & $8.3^{+}$ & $14.3^{+}$ & Carvalho, $1991^{12)}$ \\
\hline GP & SP & 16 & $14.3^{+}$ & $16.1^{+}$ & Minelli and Ribeiro, 1996 \\
\hline GP & RJ & 26 & nd $-4.4^{+++}$ & nd $-4.4^{+++}$ & Paumgartten et al., 19987) \\
\hline $\mathrm{GP}^{\#}$ & RJ & 177 & $5.1^{+}$ & $5.1^{+}$ & Mendonça et al., 19999) \\
\hline $\mathrm{GP}^{\# \#}$ & RJ & 350 & $4.8^{+}$ & $4.8^{+}$ & Mendonça et al., 19999) \\
\hline GP & RJ & 31 & nd-10.2 $2^{+++}$ & nd-10.2 $2^{+++}$ & Delgado et al., 2002 ${ }^{10)}$ \\
\hline \multicolumn{6}{|c|}{ Occupationally exposed individuals } \\
\hline AW & BA & 10 & $16.0^{+}$ & $18.1^{+}$ & Carvalho, $1991^{12)}$ \\
\hline AW & BA & 19 & $18.0^{+}$ & $18.0^{+}$ & Carvalho, $1991^{12)}$ \\
\hline $\mathrm{VC}$ & BA & 15 & $47.7^{+}$ & $112.8^{+}$ & Carvalho, $1991^{12)}$ \\
\hline $\mathrm{VC}$ & BA & 14 & $344.4^{+}$ & $702.7^{+}$ & Carvalho, $1991^{12)}$ \\
\hline $\mathrm{VC}$ & SP & 26 & $64.3^{+}$ & $76.9^{+}$ & Minelli and Ribeiro, $1996^{13)}$ \\
\hline $\mathrm{VC}^{*}$ & MG & 106 & $1.6-592.9^{+++}$ & - & Franklin and Peixoto, 1988 \\
\hline $\mathrm{VC}^{\mathrm{a}}$ & MT & 41 & $\begin{array}{c}107.3 \\
(7.5-518.5)^{++}\end{array}$ & $\begin{array}{c}135.5 \\
(7.5-875.5)^{++}\end{array}$ & Dores et al., 2003 24) \\
\hline $\mathrm{VC}^{\mathrm{b}}$ & MT & 20 & $\begin{array}{c}102.7 \\
(34.5-374.0)^{++}\end{array}$ & $\begin{array}{c}147.7 \\
(34.5-562.3)^{++}\end{array}$ & Dores et al., 2003 ${ }^{\mathrm{d} 44}$ \\
\hline $\mathrm{VC}^{\mathrm{c}}$ & MT & 13 & $14.7(\text { nd-94.8) })^{++}$ & $22.5(\text { nd }-94.8)^{++}$ & Dores et al., 2003 ${ }^{\mathrm{d} 24)}$ \\
\hline $\mathrm{VC}^{* *}$ & PA & 110 & $\begin{array}{c}156.9^{+} \\
119.8 \\
(4.6-513.8)^{++}\end{array}$ & $\begin{array}{c}231.5^{+} \\
184.8 \\
(5.3-3839.8)^{++}\end{array}$ & This study, 1997 \\
\hline $\mathrm{VC} * *$ & PA & 117 & $\begin{array}{c}39.4+ \\
27.7 \\
(2.3-284.1)^{++}\end{array}$ & $\begin{array}{c}50.4^{+} \\
32.8 \\
(3.3-357.9)^{++}\end{array}$ & This study, 2001 \\
\hline
\end{tabular}

$\mathrm{GP}=$ general population, $\mathrm{AW}=$ agricultural workers, $\mathrm{VC}=$ vector control workers. * Vector control workers from former SUCAM. ** Workers from FNS in Para state. ${ }^{\#}$ Women with breast cancer. ${ }^{\# \#}$ Women from the respective healthy control

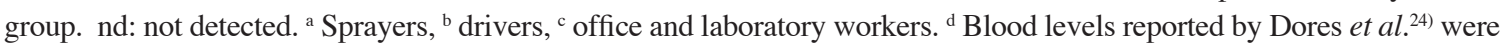
obtained in 1999. Concentrations are shown as means ${ }^{+}$, medians and range (minimum, maximum) $)^{++}$, or range only ${ }^{+++}$.

or even months after the last use, on workers' hands and other uncovered skin areas from where it can be recovered for analysis by rinsing them with n-hexane ${ }^{16)}$. In the Amazon region, malaria control sprayers often spent long periods far from home, wore the same clothes for days before washing, and frequently had their meals inside or nearby the houses they had just sprayed. Taking into account these occupational circumstances, it seems fair to think that food eaten by malaria control sprayers was contaminated with DDT residues deposited on workers' hands and clothes and contributed to their high $\sum$-DDT body burden.

\section{Elimination half-life of $p p^{\prime}-D D E$}

In humans, dichlordiphenyltrichloroethane (DDT) is converted into dichlorodiphenyldichloroethane (DDD) or, at a much slower rate, into dichlorodiphenyldichloroethylene (DDE). The primary metabolite (DDD) is degraded to 2,2-bis ( $p$-chlorophenyl)-acetic acid (DDA), which is readily excreted via urine, while further metabolism of DDE is rather slow. The general population is currently exposed to DDT almost exclusively through the diet in which DDT residues are found as $p p^{\prime}$-DDE in dairy products, eggs and meat. In contrast to the general population, the public health workers were primarily exposed to technical DDT which contained predominantly 
$p p$ '-DDT and only tiny amounts of $p p$ ' DDE.

Despite the relevance of toxicokinetic variables for environmental epidemiology, there have been few studies providing estimations of half-life values for DDT and its derivatives in human populations. Furthermore, in most cases these estimations of DDT half-life were based on only two blood level determinations and the interval between measurements was too short to establish a halflife. As pointed out by Kim and Dubin ${ }^{17)}$, to assess half-life the optimal time interval between measurements is one half-life. In the present study, half-life values for $p p$ '-DDE were calculated taking into account three serial measurements of blood levels during the elimination phase, i.e., 1997-2001, when the substantial exposure at the workplace had already been discontinued. Time intervals between the first and the second and between the second and the third blood donations were 12 and $27 \mathrm{mo}$, respectively. Therefore, the duration of the interval between the second and the third measurements was not far from the mean half-life value for $p p$ '-DDE (29.5 mo) found in this group of workers.

The elimination $\mathrm{t}_{1 / 2}$ for $p p$ '-DDE estimated for malaria control spraymen (median $=2.0 \mathrm{yr}$, mean $\approx 2.5 \mathrm{yr}$ ) in this study was shorter than that (median $=8.6 \mathrm{yr}$ ) previously reported for healthy women from the general population enrolled in a breast cancer study ${ }^{8)}$. The long half-life of $p p$ '-DDE found in that study is consistent with the half-life value of $11.7 \mathrm{yr}$ estimated from assembled data (i.e., crosssectional data on blood levels for control women between late 1960s and mid 1990s) from several breast cancer studies $^{8}$. Although they reflect the rate of decline of $p p$ 'DDE body burden, these longer half-life values do not exactly reflect the rate of clearance from the body because ingestion of $p p$ '-DDE residues via diet continued during the period of sequential blood samplings, i.e., during the "elimination phase". Moreover, the background exposure of the general population has been declining because levels of $p p$ '-DDE in food are slowly decreasing due to the global ban or drastic restriction on the use of DDT in agriculture in the 1970s. Under these circumstances, the rate of $p p$ 'DDE body burden decline reflects the rate of reduction of daily intake during the period rather than the rate of elimination from the body. The half-life values for $p p^{\prime}-$ DDE reported here are possibly closer to the real elimination half-life because the heavy exposure of malaria control workers ceased before or about the time of the first blood sampling and the magnitude of the background exposure that continued afterwards - via $p p^{\prime}$ DDE residues in food-was comparatively far less important.

Body weight fluctuations may change the volume distribution (Vd) of $p p$ '-DDE thereby modifying its levels in the blood and tissues. Therefore, elevations or reductions of BMI during the period of blood level determinations may have shortened or lengthened the estimated half-life value. Since no data was available on the body weight of malaria control workers in 1997, BMI was calculated only at the time of the last blood donation in 2001. Therefore, alterations of BMI during 1997-2001 is one of the factors that may have contributed to the wide inter-individual variability of half-life values for $p p$ '-DDE noted in this study.

No evidence of association of $p p$ '-DDE half-life either with the age or with the BMI of malaria control workers was found in this study. Wolff et al. ${ }^{8)}$ reported that $p p^{\prime}$ DDE half-life was positively associated with the BMI of women in the control group of a breast cancer study, i.e., the leaner the woman the shorter the half-life. It is of note that, in the same study, the authors found no association of half-life of PCBs with BMI ${ }^{8}$. The relationship between BMI and alterations of levels of highly persistent organochlorine compounds in the general population was discussed by Wolff and coworkers in a further article ${ }^{18)}$. It remains obscure, nevertheless, how BMI - assuming that there was no body weight change during the period - would influence the rate of clearance of $p p$ '-DDE.

Except for transfer through mother's milk, the mechanism(s) by which $p p^{\prime}$-DDE is cleared from the body is (are) far from entirely clear. Nonetheless, it has long been reported that $p p^{\prime}$-DDT and $p p$ '-DDE are potent phenobarbital-like inducers of liver cytochrome P450s (e.g., CY2B and 3A) ${ }^{19)}$, and also that treatment with phenobarbital accelerates the elimination of $p p^{\prime}-\mathrm{DDE}^{20)}$. If exposure to DDT and $p p$ '-DDE enhances their metabolism by inducing liver CYP2B and 3A isoforms, it is plausible that half-lives estimated at high exposure levels would tend to be shorter than those estimated at much lower exposure levels, provided that elimination still follows first-order kinetics at these high levels. Actually, a study of volunteer adult males, who ingested DDT at doses between 3.5 and $35.0 \mathrm{mg} /$ person/ day and accumulated DDT in the fat tissue, indicated that, after dosing was stopped, the rate of DDT loss was slower at lower storage levels ${ }^{14)}$.

Relation between DDT exposure levels and health status A retrospective diagnosis of severe (acute) poisoning by DDT was made for one insecticide sprayer who, in November 1997, presented extremely high blood levels of DDT $(3,839.8 \mu \mathrm{g} / l)$ coincident with tonic clonic seizures (treated with phenobarbital and carbamazepine) and an abnormal EEG. Convulsive symptoms and EEG abnormalities were no longer apparent a few months later when $\Sigma$-DDT levels had drastically fallen to $479.1 \mu \mathrm{g} / \mathrm{l}$ (May 1998). In May 2001, this worker's blood serum level of $\Sigma$-DDT was $15.5 \mu \mathrm{g} / l(8.1 \mu \mathrm{g} / l$ as $p p$ '-DDE) and a new EEG exam showed no abnormalities. Except for the aforementioned case of severe poisoning, relations between DDT exposure levels and health status were not clear. 
The medical evaluation of malaria control sprayers performed in May 2001 revealed several past and current health problems possibly related to their occupation and working conditions in the Amazon region. Malaria was a relatively common illness among them and 91 insecticide sprayers (of 119 examined workers) had had multiple treated episodes of the disease they worked against. Hypertension, alcoholism, neuropsychological symptoms such as depression, anxiety and insomnia, and overweight and obesity were also highly prevalent among these malaria control workers. Owing to the lack of data for appropriate unexposed controls, and the relatively small sample size for stratification of exposure levels, we did not test hypotheses on possible associations of DDT exposure with the foregoing health problems. Nonetheless, our data suggest that DDT exposure occurred concomitantly with several work-related co-morbidities in this group of Amazonian workers.

\section{Concluding remarks}

The data of this study show that levels of $\sum$-DDT and $p p$ '-DDE in the blood of malaria control workers were much higher than those found in the general population in Brazil. It was also shown that, after DDT use was discontinued in 1997, workers' blood levels of $\Sigma$-DDT and $p p$ '-DDE fell, while the $p p^{\prime}$-DDE/ $\Sigma$-DDT ratio increased, thereby supporting the view that the high $p p$ '-DDE body burden arose essentially from the occupational exposure. The biological half-life value of $p p^{\prime}$-DDE estimated for this group of DDT sprayers was shorter than half-lives previously estimated in people exposed to markedly lower environmental levels. The wide variability of half-life values among workers suggests that blood levels of DDT and $p p$ '-DDE at a given point in time, in the absence of additional kinetic parameters, are poor indicators of differences among subjects regarding past exposures. The exposure prior to blood donation would be underestimated if the subject eliminated DDT rapidly (short half-life); on the other hand, the exposure would be overestimated if the subject eliminated DDT slowly (long half-life). Therefore, the use of a single measurement of blood levels of DDT/DDE as a biomarker of exposure may eventually lead to misclassification of exposures in cross-sectional epidemiology studies.

Acknowledgments: The authors are thankful to Dr Sergio N. Kuriyama for his help in preparing the manuscript. CPF was a postgraduate student (MSc) of the National School of Public Health-FIOCRUZ, Rio de Janeiro, Brazil. FJRP was the recipient of a research fellowship from CNPq (Brazilian National Research Council).

\section{References}

1) Deane LM. Malaria studies and control in Brazil. Am J
Trop Med Hyg 1988; 38: 223-30.

2) Situação epidemiológica da malária no Brasil - 2006. Secretaria de Vigilância em Saúde / SVS - Ministério da Saúde, Brasil. [Online]. 2006 [cited 2010 Aug 16] Available from: URL: http://www.saude.gov.br/svs

3) Fundação Nacional de Saúde (FNS National Foundation of Health / Ministry of Heath), Internal Directive 164 CCDTV/DEOPE from March 3rd, 1997.

4) Ministry of Agriculture Directive 329 from September 2, 1985. Diário Oficial da União, Brasilia, D.F.: September 3rd, Section 1, p.12941.

5) Brazil- Ministry of Health Directive 11 from January 8 , 1998. Diário Oficial da União, Brasilia, D.F.: January 1st, Section 1, p.2.

6) Federal Law Nr. 11936 from May 14, 2009. Diário Oficial da União, Brasilia, D.F., May 15, 2009.

7) Paumgartten FJR, Delgado IF, Oliveira ES, Alleluia IB, Barretto HHC, Kussumi TA. Levels of organochlorine pesticides in the blood serum of agricultural workers from Rio de Janeiro, Brazil. Cad Saude Publica 1998; 14 (Suppl 3): 33-9.

8) Wolff, MS, Zeleniuch-Jacquotte A, Dubin N, Toniolo P. Risk of breast cancer and organochlorine exposure. Cancer Epidemiol Biomarkers Prev 2000; 9: 271-7.

9) Mendonça GA, Eluf-Neto J, Andrada-Serpa MJ, et al. Organochlorines and breast cancer: a case control study in Brazil. Int J Cancer 1999; 83: 596-600.

10) Delgado IF, Barretto HH, Kussumi TA, Alleluia IB, Baggio CA, Paumgartten FJR. Serum levels of organochlorine pesticides and polychlorinated biphenyls among inhabitants of Greater Metropolitan Rio de Janeiro, Brazil. Cad Saude Publica 2002; 18: 519-24.

11) Fernícola NA, Azevedo FA. Serum levels of organochlorine insecticides in humans in São Paulo, Brazil. Vet Hum Toxicol 1982; 24: 91-3.

12) Carvalho WA. Fatores de risco relacionados com exposição ocupacional e ambiental a inseticidas organoclorados no estado da Bahia, Brasil, 1985. Bol Of Sanit Panam 1991; 111: 512-24.

13) Minelli EV, Ribeiro ML. DDT and $\mathrm{HCH}$ residues in the blood serum of malaria control sprayers. Bull Environ Contam Toxicol 1996; 57, 691-6.

14) Hayes WJ, Laws ER. Handbook of pesticide toxicology, Academic Press, Inc.; 1991. p.743-80.

15) WHO (World Health Organization) DDT and its derivatives. Environmental Health Criteria 9. Geneva: World Health Organization; 1979. p.194.

16) Kazen C, Bloomer A, Welch R, Oudbier A, Price H. Persistence of pesticides on the hands of some occupationally exposed people. Arch Environ Health 1974; 29: 315-8.

17) Kim MY, Dubin N. Study design and sample size considerations for half-life studies. Arch Environ Contam Toxicol 1996; 30: 423-9.

18) Wolff MS, Anderson HA, Britton JA, Rothman N. Pharmacokinetic variability and modern epidemiology - The example of dichlorodiphenyltrichloroethane, body mass index, and birth cohort. Cancer Epidemiol Biomarkers Prev 2007; 16: 1925-30.

19) Wyde ME, Bartolucci E, Ueda A, et al. The 
environmental pollutant 1,1-dichloro-2,2-bis (p-chlorophenyl) ethylene induces rat hepatic cytochrome P450 2B and 3A expression through the constitutive androstane receptor and pregnane $\mathrm{X}$ receptor. $\mathrm{Mol}$ Pharmacol 2003; 64: 474-81.

20) Davies JE, Edmundson WF, Carter CH, Barquet A. Effect of anticonvulsant drugs on dicophane (D.D.T.) residues in man. Lancet 1969; 2: 7-9.

21) Almeida WF. Níveis Sangüíneos de DDT em Indivíduos Profissionalmente Expostos e em Pessoas sem Exposição Direta a este Inseticida no Brasil. PhD thesis, 1972, Faculty of Public Health, University of São Paulo, São Paulo, SP, Brazil.
22) Lara WH, Barretto HCC, Inomata ONK. Níveis de pesticidas organoclorados em soro sanguíneo de pessoas expostas à doença de Chagas no Brasil. Revista do Instituto Adolfo Lutz 1987; 47: 19-24.

23) Franklin $\mathrm{HMOH}$, Peixoto TMAG. Níveis sangüíneos de HCH e DDT em guardas da SUCAM. Revista da Sociedade Brasileira de Toxicologia 1988; 1: 6-8.

24) Dores EFGC, Carbo L, Abreu ABG. Serum DDT in malaria vector control sprayers in Mato Grosso state, Brazil. Cad Saude Publica 2003; 19: 429-37. 